\title{
To Assess Effectiveness of Progressive Muscle Relaxation Therapy on Stress Among Non Teaching Staff
}

\author{
Bibin Kurian, Diksha Hadke, Rupali Kakade, Divya Kamble, \\ Ruchika Kamble and Sandhya Kamble \\ Department of Child Health Nursing, SRMM College of Nursing, Datta \\ Meghe Institute of Medical Sciences (DU), Sawangi (M), Wardha, India \\ Smt.Radhikabai Meghe Memorial College of Nursing, DMIMS (DU), \\ Sawangi (M), Wardha, Maharashtra, India
}

\section{ABSTRACT}

Background - Stress is the emotional and physical responses of our body to the things happening near to each individual. Stress lives with skills have a broad notion and many intellectual-behavioral aspects. Generally, coping is the individual's ability to adjust with the situation or works to prevent the situation that leads to unfavorable outcomes. Mainly there are two ways to cope with stress. The first way is to concentrate on the issue in a straight way to change or modify the situation or surrounding that can lead to adverse effects. The other way is to control the thinking and actions of individual aroused from the conditions that leads to stress. There are several issue related remedial measures like intellectual and action solving ability. Objectives: 1) To assess the level of stress among non teaching staff. 2) To evaluate the effectiveness of progressive muscle relaxation therapy on stress. 3) To associate the post test level of stress with selected demographic variables. Materials and methods: Pre experimental one group pretest and posttest design was applied. Interventional analytical approach was used in the study. The study was conducted at DMIMS (DU), Sawangi (M), Wardha. 30 non teaching staffs were selected for the study by non probability convenience sampling technique. Job stress scale was used for collecting the data. Result: There was significant difference in the stress level of non-teaching staff before and after intervention. Conclusion: Progressive muscle relaxation therapy was effective in reducing the stress of the non teaching staff and none of the demographic variables were associated with the post test level of stress.

\section{KEY WORDS: STRESS, NON TEACHING STAFF, PROGRESSIVE MUSCLES RELAXATION THERAPY.}

\section{INTRODUCTION}

Stress is a multi factorial thing that is associated with the connection between the person and his/her surroundings. It can also be termed as an annoyance, how the person interacts with the annoyance and the connection between the person and his/her surroundings. It can be said that many victories had achieved from some kind of stress; but if the stress rate is high, then it leads to some unfavorable conditions like psychological disturbances, problems with sleep, pain in head, not able to focus on things, not able to remember things and not able to solve the problems

Biosc Biotech Res Comm P-ISSN: 0974-6455 E-ISSN: 2321-4007

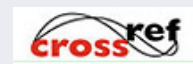

Identifiers and Pagination

Year: 2021 Vol: 14 No (9) Special Issue

Pages: 55-57

This is an open access article under Creative

Commons License Attribn 4.0 Intl (CC-BY).

DOI: $h t t p: / / d x$.doi.org/10.21786/bbrc/14.9.12 correctly. There are different varieties of stress which affects the individual negatively by affecting the sources of copying and in the future life; it will have physical and mental consequences. It is also noted that stress have physical and mental consequences, not able to function properly, not able to adjust to the situation. At the end, these all will affect the person's quality of life.

Mainly there are two ways to cope with stress. The first way is to concentrate on the issue in a straight way to change or modify the situation or surrounding that can lead to adverse effects. The other way is to control the thinking and actions of individual aroused from the conditions that leads to stress. All the living organisms experience the stress. The aim of nurse is not removing the whole stress completely, because stress is a part of life. Response to stress can be in an unhealthy way, and the role of non teaching staff at this time is helping to promote the health. Heath promotion includes strategies for reduction and management of the stress, the non
Article Information

Received: $10^{\text {th }}$ May 2021

Accepted after revision: $08^{\text {th }}$ July 2021 
teaching staff also can use nursing process in order to manage the stress.

id.

Table 1. Percentage wise distribution of non-teaching staff according to their demographic variables. $n=30$

\begin{tabular}{|c|c|c|}
\hline $\begin{array}{l}\text { Demographic } \\
\text { Variables }\end{array}$ & $\begin{array}{l}\text { No. of non- } \\
\text { teaching staff }\end{array}$ & Percentage (\%) \\
\hline \multicolumn{3}{|l|}{ Age(yrs) } \\
\hline $21-30$ yrs & 16 & 53.3 \\
\hline $31-40$ yrs & 10 & 33.3 \\
\hline $41-50$ yrs & 4 & 13.3 \\
\hline \multicolumn{3}{|l|}{ Gender } \\
\hline Male & 17 & 56.7 \\
\hline Female & 13 & 43.3 \\
\hline \multicolumn{3}{|l|}{ Residential Area } \\
\hline Urban & 22 & 73.3 \\
\hline Rural & 8 & 26.7 \\
\hline \multicolumn{3}{|l|}{ Education } \\
\hline Graduate & 13 & 43.3 \\
\hline Post Graduate & 17 & 56.7 \\
\hline \multicolumn{3}{|l|}{ Marital Status } \\
\hline Married & 22 & 73.3 \\
\hline Unmarried & 7 & 23.3 \\
\hline Divorce & 0 & 0 \\
\hline Widow & 1 & 3.3 \\
\hline \multicolumn{3}{|l|}{ Occupation } \\
\hline Permanent & 20 & 66.7 \\
\hline Contract Basis & 10 & 33.3 \\
\hline \multicolumn{3}{|l|}{ Income } \\
\hline Below Rs. 10000 & 1 & 3.3 \\
\hline Rs.10001-15000 & 8 & 26.7 \\
\hline Rs.15001-20000 & 10 & 33.3 \\
\hline Rs.20001 \&t above & 11 & 36.7 \\
\hline \multicolumn{3}{|l|}{ Experience } \\
\hline Less than 01 year & 2 & 6.7 \\
\hline 01-07 years & 13 & 43.3 \\
\hline 08-14 years & 12 & 40 \\
\hline 15 years \& more & 3 & 10 \\
\hline \multicolumn{3}{|l|}{ Type of work } \\
\hline Clerical & 20 & 66.7 \\
\hline Social & 10 & 33.3 \\
\hline \multicolumn{3}{|l|}{ Area of work } \\
\hline Hospital & 24 & 80 \\
\hline College & 6 & 20 \\
\hline
\end{tabular}

\section{MATERIAL AND METHODS}

Interventional analytical approach was used for the present study. In the present study, pre experimental one group Pre-test - post-test design was used. The study was conducted at DMIMS (DU). The sample for the present study consisted of 30 non teaching staffs working in DMIMS (DU). Non probability convenience sampling technique was used for the present study. Inclusion criteria were non teaching staff who work for more than 8 hours in front of computer daily and who are willing to participate in the study. Exclusion criteria were non teaching staff who have some health problems and who have already taken work related management measures. Job stress scale and progressive muscle relaxation technique were used to collect the data.

\section{RESULTS}

Section A: Distribution of non-teaching staff with regards to demographic variables.

Section B: Assessment of pre and post test level of stress among non-teaching staff.

Table 2. Assessment with level of pre test stress score $\mathrm{n}=30$

\begin{tabular}{|c|c|c|c|}
\hline \multirow{2}{*}{ Level of pre test stress } & \multirow{2}{*}{ Score Range } & \multicolumn{2}{|c|}{ Level of Pre test stress Score } \\
\cline { 3 - 4 } & & No of non-teaching staff & Percentage \\
\hline No Stress & $0-12$ & 0 & 0 \\
\hline Mild Stress & $13-25$ & 0 & 0 \\
\hline Moderate Stress & $26-38$ & 1 & 3.33 \\
\hline Severe Stress & $39-51$ & 29 & 96.67 \\
\hline \multicolumn{2}{|c|}{ Minimum score } & \multicolumn{2}{|c|}{51} \\
\hline \multicolumn{2}{|c|}{ Maximum score } & $43.50 \pm 3.87$ \\
\hline \multicolumn{2}{|c|}{ Mean stress score } & \multicolumn{3}{|c|}{} \\
\hline
\end{tabular}

Table 3. Assessment with level of post test stress score $\mathrm{n}=30$

\begin{tabular}{|c|c|c|c|}
\hline \multirow{2}{*}{ Level of post test stress } & \multirow{2}{*}{ Score Range } & \multicolumn{2}{|c|}{ Level of Post test stress Score } \\
\cline { 3 - 4 } & & No of non-teaching staff & Percentage \\
\hline No Stress & $0-12$ & 0 & 0 \\
\hline Mild Stress & $13-25$ & 12 & 40 \\
\hline Moderate Stress & $26-38$ & 18 & 60 \\
\hline Severe Stress & $39-51$ & 0 & 0 \\
\hline Minimum score & \multicolumn{2}{|c|}{25} \\
\hline Maximum score & \multicolumn{2}{|c|}{31} \\
\hline Mean stress score & \multicolumn{2}{|c|}{$28.60 \pm 2.98$} \\
\hline
\end{tabular}

Table 4. Significance of difference between stress score in pre and post test of non-teaching staff $n=30$

\begin{tabular}{|c|c|c|c|c|c|}
\hline Overall & Mean & SD & $\begin{array}{c}\text { Mean } \\
\text { Difference }\end{array}$ & $\begin{array}{c}\mathrm{t}- \\
\text { value }\end{array}$ & $\begin{array}{c}\mathrm{p}- \\
\text { value }\end{array}$ \\
\hline Pre Test & 43.50 & 3.87 & $14.90 \pm 4.63$ & 17.61 & $\begin{array}{l}0.0001 \\
\text { S,p<0.05 }\end{array}$ \\
\hline
\end{tabular}

Section C: Evaluation of effectiveness of progressive muscle relaxation therapy on stress among non-teaching staff.

This table shows the comparison of pretest and post test stress scores of non-teaching staff. Mean, standard deviation and mean difference values are compared and student's paired't' test is applied at 5\% level of significance. The tabulated value for $n=30-1$ i.e. 29 degrees of freedom was 2.05. The calculated 't' value 
i.e. 17.61 are much higher than the tabulated value at $5 \%$ level of significance for overall stress score of nonteaching staff which is statistically acceptable level of significance. Hence it is statistically interpreted that the progressive relaxation muscle therapy on stress among non-teaching staff was effective. Thus hypothesis $\mathrm{H} 1$ is accepted.

Section D: Association of post test level of stress among non-teaching staff with their demographic variables. None of the demographic variables were associated with the post test level of stress.

\section{DISCUSSION}

Analysis of data showed that there was significant difference in the stress level of non-teaching staff before and after intervention. Hence it is concluded that progressive muscle relaxation therapy significantly brought improvement in the stress level of non-teaching staff. Progressive muscle relaxation therapy was given to the nursing students studying at selected Nursing Colleges in Bangalore for assessing whether it was effective in reducing the stress or not. The mean pre test stress score was 89.56 and the mean post test stress score was 65.74. The mean post test stress score was less than the mean pre test stress score. This indicates that progressive muscle relaxation therapy was effective in reducing the stress of the nursing students.

Implication: The findings of the study have implications for nursing practice, nursing education, nursing administration and nursing research.

Nursing Practice: Progressive muscle relaxation therapy is an inexpensive intervention in order to reduce stress. The nurses can provide awareness to the people regarding this intervention. Nurses should have skill regarding various therapies other than medicine to help the clients and families to relieve their stress which in turn helps in preventing psychiatric illness and making their life more hopeful even though affected by illness.

Nursing Education: The healthcare delivery system at present gives more emphasis on preventive care rather than curative aspect. Progressive muscle relaxation therapy can be used to teach as a stress reduction method to student nurses, patients, and caregivers of clients. Nursing students should be trained to acquire skill in assessing the stress of clients in different settings and to intervene with the appropriate literature so that they can be prevented from taking anti depressive other medicines to relieve their stress.

Nursing Research: Many more research studies could be done to assess the efficacy of this highly feasible and less expensive therapy in various other conditions and settings. The researchers can also explore similar therapies which increase the self-confidence and selfworth of sample. Future investigators can use the findings and the methodology as reference material.

Nursing Administration: The administrative nursing can also provide training of progressive muscle relaxation therapy for staff nurses, student nurses and other allied profession. The nurse authors should take a keen interest in progressive muscle relaxation therapy for the effective use in various areas like clinical practice, community and home health care.

\section{Recommendations}

The current study has following recommendations:

- The study can be conducted for larger sample size which will facilitate more reliable result.

- A similar study can be conducted in different settings.

- The experimental study can be conducted to find out the effectiveness of Progressive Muscles Relaxation Therapy on stress among caregivers of mentally ill patient.

- The effectiveness of Progressive Muscles Relaxation Therapy can be done in reducing stress among cancer patients admitted in hospitals.

- A similar study can be conducted to find out the Stress and coping strategies of hospice nursing.

- A comparative study can be conducted to find out the level of stress among staff nurses working in the selected government and private hospitals.

- A similar study can be done with large sample size.

- A similar study can be conducted to find out the level of stress among staff nurses working in the Mental Health Hospitals and General Hospitals.

\section{REFERENCES}

Beddoe AE, Murphy SO.( 2004) Does mindfulness decrease stress and foster empathy among nursing students J Nurs Educ., 43(7):305-12.

Eby L, Brown NJ. (2009) Mental health nursing care. In: Elder R, Evans K, Nizette D, editors. Psychiatric and mental health nursing. Sydney: Elsevier, Mosby; p. 68.

Forozandeh N, Delaram M. ( 2003) Effect of cognitive behavioral therapy on coping methods non-medical student university of medical sciences. Shahre Kord University of Medical Sciences Journal, 5(3):26-34.

Gammon J, Morgan-Samuel H. (2005) A study to ascertain the effect of structured student tutorial support on student stress, self-esteem and coping. Nurse Educ Pract, 5(3):161-171.

https://www.ijhsr.org/IJHSR_Vol.9_Issue.11_ Nov2019/25.pdf 